\title{
Origanum vulgare L. extract-mediated synthesis of silver nanoparticles, their characterization and antibacterial activities
}

\author{
Syuzanna Hambardzumyan ${ }^{1,2}$, Naira Sahakyan ${ }^{1}$, Margarit Petrosyan ${ }^{1}$, Muhammad Jawad Nasim², Claus Jacob² \\ and Armen Trchounian ${ }^{1 *}$ (1)
}

\begin{abstract}
Plant extracts serve as reducing and coating agents and are, therefore, commonly employed for the generation of silver (Ag) nanoparticles (NPs). Plant extract mediated synthesis of Ag NPs is a green, environmentally friendly and cost-effective technique which offers a new and potential alternative to chemically synthesized NPs, decreasing the utilization of hazardous and toxic chemicals and protecting the environment. Origanum vulgare L. extracts were evaluated for total flavonoid and phenol content. The free radical scavenging activity was determined employing 2,2-diphenyl-1-picrylhydrazyl assay. Ag NPs were produced exploiting ethanolic extracts of O. vulgare L. leaves. The generation of Ag NPs was carried out both in light and dark conditions. The biosynthesized Ag NPs were characterized employing microscopic and spectroscopic techniques. Antibacterial activities of Ag NPs were determined following appropriate methods. The results revealed that energy of photons was required to reduce $\mathrm{Ag}^{+}$to $\mathrm{Ag}^{0}$. $\mathrm{According}$ to scanning electron microscopy reports, biologically formed Ag NPs ranged in size from 1 to 50 nmand were presented instability causing aggregation. They indicated that $O$. vulgare L. extracts were rich in flavonoids and phenols and exhibited strong antioxidant activity. Ag NPs exhibited good antibacterial activity immediately after production. Grampositive strains showed higher sensitivity to Ag NPs compared to Gram-negative stains. Ag NPs can serve as an effective antibacterial agent against antibiotic-resistant strains. The kanamycin-resistant strain was more sensitive to Ag NPs than the ampicillin-resistant strain. Thus, Origanum extract-mediated synthesized Ag NPs can be recommended as alternative effective antibacterial agents, but their activity depended on bacterial species and strains.
\end{abstract}

Keywords: Origanum vulgare L., Leaf extract and phenol content, Antioxidant activity, Plant extract mediated synthesis of silver nanoparticles, Antibacterial activity

\section{Key points}

1. Biosynthesis of quality Ag nanoparticles (NPs) using $O$. vulgare L. leaf extracts under light condition.

2. Significant inhibition of the growth of Gram-positive, Gram-negative bacteria and antibiotic-resistant strains by Ag NPs exploited.

*Correspondence: Trchounian@ysu.am

${ }^{1}$ Department of Biochemistry, Microbiology and Biotechnology, Biology

Faculty, Yerevan State University, 1 Alex Manoogian Str, 0025 Yerevan,

Armenia

Full list of author information is available at the end of the article

\section{Introduction}

The emergence of resistance to currently available antibiotics is a huge challenge faced by the humanity. According to estimates by the European Center for Disease Prevention and Control, 25,000 people die in Europe from drug-resistant bacterial infections every year. The most recent pandemic Covid-19 situation which has affected more than twenty million people across the globe until now is the latest example which highlights the need to develop cure against these species. The emergence of resistance has, therefore, provoked the need to 
develop alternative agents against the pathogenic bacterial strains (Trchounian et al. 2018; Kraemer et al. 2019).

Silver $(\mathrm{Ag})$ is a unique multi-purpose element which was commonly exploited to prepare coins and jewelry. Evidence of the antibacterial properties of silver also dates back to ancient times, as testified by various historical stories well known to the public (Alexander, 2009). In recent years, the utilization of Ag nanoparticles (NPs) for medical purposes has attracted great attention of researchers because of their exceptional antimicrobial activities especially against a wide range of pathogenic microorganisms (Srirangam and Rao 2017; Trchounian et al. 2018).

Generally, $\mathrm{Ag}^{+}$is a notorious toxic ion which causes oxidative stress and damages in various cellular components, including DNA, proteins, and the cell membrane. Elemental Ag NPs, in contrast, serve as an interesting dosage form characterized by a slower dissolution rate, which provides continuous intracellular supply of $\mathrm{Ag}^{+}$ leading to the death of target microorganisms (Mcshan et al. 2014) although some authors conclude that the mechanisms of action of $\mathrm{Ag}^{+}$and Ag NPs may be not identical (Anna et al. 2018).

There are several methods for the generating Ag NPs, including physical grinding, wet-chemical reactions and biological methods. Physical methods usually generate very stable and small Ag NPs in high concentrations. The physical methods are, however, generally associated with numerous disadvantages. The most promising disadvantage includes the irreversible harm to the environment since such methods generally consume substantial amount of energy (Dhand et al. 2015). Similarly, the chemical methods also pose severe burden to the environment. Reagents frequently employed in chemical methods, such as reducing agents (sodium borohydride and hydrazine), stabilizers (for example, thiols, acids, alcohols) and solvents are inherently hazardous and harmful to the environment (Kondeti et al. 2017). The biological methods, in contrast, are rather simple, fast, inexpensive, energy efficient and do not threaten the environment (Tarannum and Gautam 2019). Ag NPs are biologically synthesized exploiting various microorganisms (yeast, fungi and bacteria) and extracts of plant tissues (leaves, roots, fruits, stems and flowers etc.). Among biological methods, plant extract-based production of Ag NPs seems more justified. In addition to other advantages of the synthesis of Ag NPs mediated by the plant extracts, secondary metabolites present in the plant extracts as coating agents with antioxidant activity may reduce the side effects of Ag NPs, making them more suitable for medical applications (Shaik et al., 2018; MoghrovyanA et al. 2019; Aghajanyan et al., 2020). Plant extracts contain various natural phytochemicals, such as water-soluble flavonoids and polyphenolic compounds, which serve as antioxidants. These phyto-molecules are strongly reducing in nature and easily adsorb at the surface of NPs, thereby enhancing their stability (Salari et al. 2019). In addition, plant-based antioxidants prevent the oxidation of $\mathrm{Ag}$ atoms $\left(\mathrm{Ag}^{0}\right)$ at the surface of NPs by forming a protective coating around the particles and thereby avoiding direct interaction with molecular oxygen. If these coating components are not firmly adhered to the surface of the NPs and displaced by solvent molecules, the physical and chemical stability of NPs is adversely affected leading to aggregation or oxidation (Mcshan et al., 2014; Aghajanyan et al. 2020). O. vulgare L., belonging to the Lamiaceae family as a major source of natural secondary metabolites with redox properties, can be effectively used for the synthesis of Ag NPs (MoghrovyanA et al. 2019).

In the current study, a culinary herb $O$. vulgare $\mathrm{L}$. was collected from four different provinces of Armenia i.e. Kotayk, Lori, Tavush, Gegharkunik, and its ethanolic extract was employed for green synthesis of Ag NPs. The ethanolic extract of $O$. vulgare $\mathrm{L}$. is rich in polyphenols, which contribute to its reducing potential. The biosynthesized Ag NPs were characterized and quantified by several techniques, such as UV-Vis spectrophotometry, Dynamic Light Scattering (DLS) and Laser Diffraction (LD), Scanning Electron Microscopy (SEM) couple with Energy Dispersive X-ray (EDX) analysis, Inductively Coupled Plasma-optical emission spectrometry (ICPOES). Moreover, the potential antibacterial properties of Ag NPs were evaluated against various Gram-positive (Staphylococcus aureus, Bacillus subtilis), Gram-negative bacterial strains (Escherichia coli, Salmonella typhimurium), ampicillin-resistant $E$. coli, and kanamycin-resistant $E$. coli stains. The growth kinetics of $E$. coli when exposed to plant extract and Ag NP were also studied.

\section{Materials and methods}

\section{Plant materials and preparation of $O$. vulgare extracts}

The plant material (O. vulgare L.) was collected from four provinces of Armenia; Kotayk (OV 1), Lori (OV 2), Tavush (OV 3), Gegharkunik (OV 4) during bloom in July 2016. The identification of plant samples was carried out at the Department of Pharmacognosy, Yerevan State Medical University, Yerevan (Armenia). Plant samples were deposited and are available at the Herbarium of the Institute of Botany, National Academy of Sciences of Armenia, Yerevan, Armenia (Voucher specimen number: ERE191395). The collected leaves were washed, dried in the shadow at room temperature and subsequently crushed to obtain powder which was stored in a dry and dark place at room temperature until use.

$1 \mathrm{~g}$ of $O$. vulgare leaves powder was weighed and suspended into $10-15 \mathrm{~mL}$ of $40 \%$ ethanol and stirred 
overnight at $\sim 10{ }^{\circ} \mathrm{C}$. The extract was subsequently centrifuged for $5 \mathrm{~min}$ at $5000 \mathrm{rpm}$, and the supernatant was isolated. The precipitate was extracted four times with the same procedure, and the combined supernatant fractions were evaporated at room temperature to obtain dried extracts which were then stored at $4^{\circ} \mathrm{C}$ until further use.

\section{Determination of total flavonoid content}

The total flavonoid content of O. vulgare plant extracts was determined employing $\mathrm{AlCl}_{3}$ colorimetric assay (Ghasemi et al. 2009). The extract was dissolved in $80 \%$ ethanol to obtain a final concentration of $1 \mathrm{mg} \mathrm{mL} L^{-1}$. $0.5 \mathrm{~mL}$ of this extract solution was mixed with $0.1 \mathrm{~mL}$ of $\mathrm{AlCl}_{3}(10 \%), 0.1 \mathrm{~mL}$ of sodium acetate $(1 \mathrm{M})$ and $2.8 \mathrm{~mL}$ of distilled water. The sample was incubated for $15 \mathrm{~min}$ and the absorbance of the samples was measured at $415 \mathrm{~nm}$ against a blank consisting of distilled water utilizing a UV-Vis spectrophotometer (Genesys 10S, Thermo Scientific, USA). Total flavonoid content was determined employing a calibration curve of quercetin (Q), as a reference flavonoid $\left(0-1000 \mu \mathrm{g} \mathrm{mL} \mathrm{m}^{-1}\right)$ and results were expressed in terms of $\mathrm{Q}$ equivalents $(\mathrm{QE})$ per g extract dry weight.

\section{Determination of total phenolic content}

The total phenolic content of plant extracts was measured exploiting the Folin-Ciocalteu (FC) reagent according to the method described by Genwali et al. (2013). The plant extract was dissolved in distilled water to obtain a final concentration of $1 \mathrm{mg} \mathrm{mL}{ }^{-1} .0 .5 \mathrm{~mL}$ of plant extracts solution was mixed with $0.1 \mathrm{~mL}$ of FC reagent and incubated for $7 \mathrm{~min}$ at room temperature followed by the addition of $1 \mathrm{~mL}$ of $\mathrm{Na}_{2} \mathrm{CO}_{3}$ solution (7\%) and $0.9 \mathrm{~mL}$ of distilled water. The mixture was shaken thoroughly and kept in the dark at room temperature for $1 \mathrm{~h}$. The absorbance of samples was measured at $765 \mathrm{~nm}$ using a UV-Vis spectrophotometer (Genesys 10S, Thermo Scientific, USA). Distilled water was exploited as a blank. Total phenolic content was determined employing a calibration curve of gallic acid (GA) $\left(0-250 \mu \mathrm{g} \mathrm{mL}^{-1}\right)$. The total phenolic content was expressed in terms of GA equivalents (GAE) per g extract dry weight.

\section{2,2-Diphenyl-1-picrylhydrazyl free radical scavenging assay}

Free radical scavenging activity of different $O$. vulgare leave extracts was measured by 2,2-Diphenyl-1-picrylhydrazyl (DPPH)-free radical scavenging assay (Xu et al. 2011). Various concentrations of plant extracts (ranging from 31.25 to $500 \mu \mathrm{g} \mathrm{mL}^{-1}$ ) were prepared by dilution method 0.0.1 mM DPPH was prepared in $96 \%$ ethanol. $200 \mu \mathrm{L}$ of aqueous plant extracts of different concentrations were added to $1 \mathrm{~mL}$ of DPPH solution. The mixture was shaken vigorously and allowed to stand in dark condition at room temperature for $30 \mathrm{~min}$. The absorbance was measured at a wavelength of $517 \mathrm{~nm}$ against a blank (96\% ethanol) using a UV-Vis spectrophotometer (Genesys 10S, Thermo Scientific, USA). Catechin was used as a positive control under the same assay condition. The radical scavenging activity was calculated employing the following equation:

$$
\text { Radical scavenging activity }(\%)=\left[\frac{(A b c-A b s)}{A b c}\right] \times 100
$$

where $\mathrm{Abc}$ and Abs represented the absorbance of the control (DPPH solution alone) and the absorbance of the sample in the presence of an extract or standard, respectively. The results were expressed as $\mathrm{IC}_{50}$ values $\left(\mu \mathrm{gmL}^{-1}\right)$, which represented the concentration of sample required to inhibit $50 \%$ of the DPPH free radicals.

\section{Synthesis of Ag NPs using O. vulgare extracts}

Stock solution of $O$. vulgare extract was prepared by dissolving $5 \mathrm{mg}$ of plant extract in $10 \mathrm{~mL}$ of Milli-Q water $\left(18.2 \mathrm{M} \Omega \cdot \mathrm{cm}\right.$ at $\left.25^{\circ} \mathrm{C}\right)$. Ag NPs were synthesized by mixing the solutions of $\mathrm{AgNO}_{3}(10 \mathrm{mM})$ and plant extract $\left(0.5 \mathrm{mg} \mathrm{mL}^{-1}\right)$ in 1:9 ratio to achieve a final concentration of $1 \mathrm{mM}$ for $\mathrm{AgNO}_{3}$ (Rautela et al. 2019). A control sample excluding plant extract was also prepared similarly. The samples were agitated on a shaker with constant rotation $(150 \mathrm{rpm})$ under dark (no light) and light (normal room light) conditions at a temperature of $23 \pm 2{ }^{\circ} \mathrm{C}$ for $18 \mathrm{~h}$. For dark conditions, the tubes were wrapped with aluminum foil to protect from light (Srikar et al. 2016).

\section{Characterization of biosynthesized Ag NPs}

The optical properties of Ag NPs were characterized exploiting a UV-Vis spectrophotometer (Lambda 35, Perkin Elmer) with a slit width of $1 \mathrm{~nm}$ of slit width and at a scan speed of $480 \mathrm{~nm} \mathrm{~min}{ }^{-1}$. The analysis was performed employing quartz cuvettes over a path-length of $10 \mathrm{~mm}$. The absorption of samples was measured in the wavelength range $(\lambda)$ of $350-700 \mathrm{~nm}$. The device was equipped with the UV WinLab software package.

The physical stability of the samples was evaluated by measuring the zeta potential ( $\xi$-potential) and dynamic light scattering (DLS). The $\xi$-potential and DLS measurements of the samples were performed employing a Zeta-sizer Nano ZS (Malvern Instruments, UK) which analyzed the electrophoretic mobility of the samples in an electric field. The size of biosynthesized Ag NPs was imaged by SEM (ZEISS-SUPRA 40/gemini column) equipped with Electron Backscatter Diffraction (EBSD) detector and Energy Dispersive X-ray Spectroscopy 
(EDS) detector -SEM-EDX analysis. The total Ag content was determined by inductively coupled plasma-optical emission spectroscopy (ICP-OES) (Horiba Jobin-Yvon Ultima 2)).

\section{Antibacterial activity of biosynthesized Ag NPs}

The antibacterial activity of biosynthesized Ag NPs was evaluated against a plethora of microorganisms including, Gram-positive bacterial strains (S. aureus MDC 5233 (Microbial Depository Center, MDC (National Microbial Culture Collection, WDCM 803, National Academy of Sciences of Armenia, Yerevan, Armenia; laboratory control strain), B. subtilis WT-A17 (isolated from metal polluted soils of Kajaran, Armenia), Gramnegative bacterial strains (E. coli VKPM-M17 (Russian National Collection of Industrial Microorganisms at the Institute of Genetics and Selection of Industrial Microorganisms, Moscow, Russia; laboratory control strain)), S. typhimurium MDC 1754 (laboratory control strain)), ampicillin-resistant $E$. coli DH5 $\alpha$-pUC18 and kanamycinresistant E. coli pARG-25 (supplied by Scientific-Production Center "ArmBiotechnology", National Academy of Sciences of Armenia, Yerevan, Armenia) strains by disk diffusion method employing disks with $6 \mathrm{~mm}$ in diameter (Lawhavinit et al., 2010). The Mueller-Hinton agar was exploited for growth of bacteria. Disks immersed in plant extracts $\left(0.5 \mathrm{mg} \mathrm{mL}^{-1}\right)$, and $\mathrm{Ag}$ NPs solutions were placed separately on Petri dishes containing meatpeptone agar contaminated with bacteria. Distilled water was employed as a negative control whilst ampicillin $\left(20 \mu \mathrm{g} \mathrm{mL}^{-1}\right)$ was exploited as standard positive control for all cases excepted ampicillin-resistant E. coli DH5 $\alpha$ pUC18, for which kanamycin $\left(20 \mu \mathrm{g} \mathrm{mL}{ }^{-1}\right)$ was utilized. The plates were then incubated for $18 \mathrm{~h}$ at $37{ }^{\circ} \mathrm{C}$, and the diameters of bacterial growth inhibition zones were recorded in millimeter $(\mathrm{mm})$. The antibacterial activity of biosynthesized Ag NPs was compared with colloidal Ag, commercially available under "Silverton" trademark ("Tonus-Les" Lab, Armenia), and produced by electrochemical process (Soghomonyan et al., 2019). The antibacterial activity of Ag NPs was also recorded in terms of Minimum Inhibitory Concentration (MIC) two-fold serial dilution method $\left(110-6.875 \mu \mathrm{g} \mathrm{mL}{ }^{-1}\right)$. MIC values were taken after $18 \mathrm{~h}$ of incubation at $37{ }^{\circ} \mathrm{C}$. MIC value was considered as the lowest concentration of NPs, which suppressed the growth of the test-bacterium (the concentration which form the smallest inhibition zone around the disk).

\section{Growth kinetics of E. coli VKPM-M17 under the influence of biosynthesized Ag NPs}

The growth kinetics assay was employed to understand the pattern of bacterial growth under the influence of biosynthesized Ag NPs. The growth kinetics of $E$. coli VKPM-M17 was also monitored in the presence of OV 3 plant extract. Fresh $E$. coli colonies were isolated from meat-peptone agar plates and transferred to LB broth ( $\mathrm{pH}$ 7.5) followed by incubation for $18 \mathrm{~h}$ at $37^{\circ} \mathrm{C}$. The antibacterial activity of Ag NPs was estimated in terms of MIC. The antibacterial effect of extract (OV3) was monitored at the concentration which was employed to produce Ag NPs i.e. $0.5 \mathrm{mg} \mathrm{mL}^{-1}$. Bacterial growth curves were determined by measuring the turbidity of samples containing bacteria at $565 \pm 15 \mathrm{~nm}$ every $30 \mathrm{~min}$ exploiting a densitometer (DEN-1B, BIOSAN, Latvia) (SzermerOlearnik and Zwolińska 2014).

The growth rate constant $\left(\mu_{1}\right)$ and mean generation time $\left(\mathrm{g}_{1}\right)$ for $E$. coli VKPM-M17 were calculated during $\log$ growth phase $\left(\mathrm{t}_{0}=0, \mathrm{t}=1.5 \mathrm{~h}\right)$ employing the following formulas:

$$
\begin{aligned}
& \mu=\left[\left(\log _{10} \mathrm{~N}-\log _{10} \mathrm{~N}_{0}\right) \times 2.303\right] /\left(\mathrm{t}-\mathrm{t}_{0}\right) \\
& \mathrm{g}=\left(\log _{10} \mathrm{~N}_{\mathrm{t}}-\log _{10} \mathrm{~N}_{0}\right) / \log _{10} 2 \text { or } \mathrm{g}=0.693 / \mu
\end{aligned}
$$

where $\mathrm{N}$ is the number of cells (Maclean et al. 2009).

\section{Data processing}

The experimental measurements were expressed as average of three analyses calculated with \pm SD employing Microsoft Office 365. The diameters of NPs were measured exploiting Image J software. Analysis of the data distribution was performed with the Student's $t$ test. P values of less than 0.05 were considered as statistically significant.

\section{Results \\ The total flavonoid-phenolic composition of $O$. vulgare extracts}

Flavonoids and other phenolic compounds are generally associated with redox and antioxidant properties. The total content of flavonoids in different $O$. vulgare extracts was determined from the calibration curve of $\mathrm{Q}$ $\left(y=2.3083 x+0.0369, R^{2}=0.9947\right)$. A reasonable amount of flavonoid was found in all samples. The highest amount of flavonoid was observed in the sample collected from Tavush region $\left(69.65 \pm 1.09 \mathrm{mg}(\mathrm{QE}) \mathrm{g}^{-1}\right)$ followed by the sample collected from Gegharkunik region $\left(53.54 \pm 0.75 \mathrm{mg}(\mathrm{QE}) \mathrm{g}^{-1}\right)$. A rather decreased amount of flavonoid was observed in the sample collected from Lori region $\left(41.63 \pm 1.14 \mathrm{mg}(\mathrm{QE}) \mathrm{g}^{-1}\right)$ and the least quantity was found in the sample collected from Kotayk region $\left(30.22 \pm 0.25 \mathrm{mg}(\mathrm{QE}) \mathrm{g}^{-1}\right)$. Similarly, the total phenolic content of different $O$. vulgare extracts was calculated from a calibration curve of GA $(y=0.0063 x+0.0718$, 
$\mathrm{R}^{2}=0.9789$ ). A reasonable number of polyphenols was observed in all samples. The highest content of polyphenols was observed in the sample collected from Tavush region $\left(202.68 \pm 1.27 \mathrm{mg}(\mathrm{GAE}) \mathrm{g}^{-1}\right.$ ) followed by the sample collected from Lori region $(185.27 \pm 2.05 \mathrm{mg}$ (GAE) $\mathrm{g}^{-1}$ ). A rather lower content of polyphenols was observed in the sample collected from Kotayk region $\left(165.01 \pm 1.07 \mathrm{mg}(\mathrm{GAE}) \mathrm{g}^{-1}\right.$ ) and the least quantity was found in the sample collected from Gegharkunik region $\left(150.19 \pm 0.69 \mathrm{mg}(\mathrm{GAE}) \mathrm{g}^{-1}\right)$. The overall results indicate that the sample collected from Tavush region contains the highest content of polyphenols and flavonoid (Table 1).

\section{Antioxidant activity of $O$. vulgare extracts}

Since polyphenols and flavonoids are generally associated with radical scavenging activities, the four different $O$. vulgare extracts were, therefore, evaluated for DPPH-free radical scavenging activity and the results were expressed in terms of $\mathrm{IC}_{50}$ values $\left(\mu \mathrm{g} \mathrm{mL}^{-1}\right)$. All of the samples presented reasonable radical scavenging activities. The highest activity was observed for OV3 $\left(40.22 \pm 0.91 \mu \mathrm{g} \mathrm{mL}{ }^{-1}\right)$ followed by OV $2\left(49.99 \pm 1.24 \mu \mathrm{g} \mathrm{mL} \mathrm{L}^{-1}\right)$. A relatively lower radical scavenging activity was observed for OV 1 $\left(64.73 \pm 1.01 \mu \mathrm{g} \mathrm{mL}^{-1}\right)$ and the least activity was observed for OV 4 (75.99 $\pm 13 \mu \mathrm{g} \mathrm{mL} \mathrm{m}^{-1}$ ) (Fig. 1). Lower absorbance values of the reaction mixture indicated higher free radical activity. The antioxidant activity of plant extracts was compared with the antioxidant activity of catechin $\left(12.62 \mu \mathrm{g} \mathrm{mL}^{-1}\right)$, as positive control. The results are supported by several other numerous studies which confirm the notion that extracts with a high phenolic content exhibit strong antioxidant activity (Tungmunnithum et al. 2018).The highest activity was observed for OV3 $\left(40.22 \pm 0.91 \mu \mathrm{g} \mathrm{mL}^{-1}\right)$, which could be associated with the highest amount of flavonoid and polyphenols.

\section{Generation and Characterization of Ag NPs}

Four groups of Ag NPs (i.e. Ag NPs 1, Ag NPs 2, Ag NPs 3 and Ag NPs 4) were produced exploiting OV 1, OV 2, OV 3 and OV 4 extracts, respectively. The formation of Ag NPs was confirmed by exploiting UV-Vis spectroscopy based analysis. In the presence of plant extracts, the

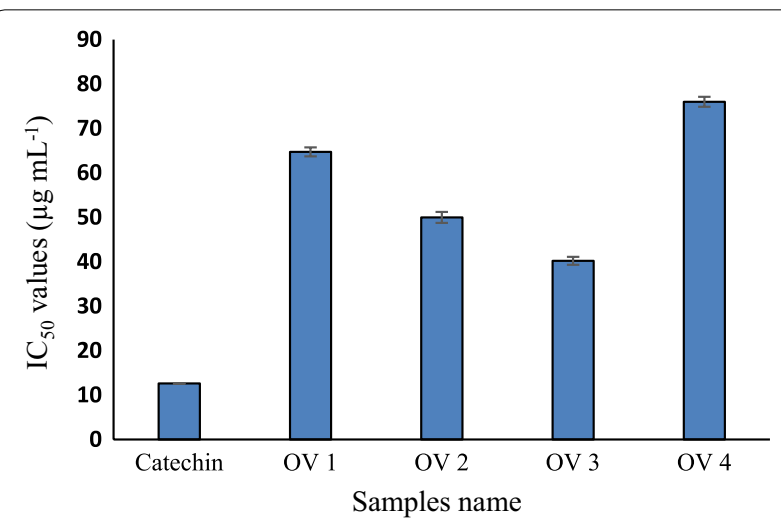

Fig. 1 DPPH-free radical scavenging activity of $O$. vulgare extracts (OV 1, OV 2, OV 3 and OV 4) and catechin. The results are expressed in terms of $\mathrm{IC}_{50}$ values indicating the concentrations required to scavenge $50 \%$ of the free radicals

color of the reaction mixture changed from light yellow to brown after $18 \mathrm{~h}$ of incubation. The previous literature about Ag NPs describes that the NPs are formed when color of the solution turns from light yellow to brown whilst a dark brown or black color indicates the possible oxidation of Ag NPs (Yong et al. 2013). The stability and shelf life of all nano-suspensions were investigated after keeping the samples in storage for more than two weeks after production. The results, however, pointed out that the samples were not very stable as indicated by the change in color of the samples (Fig. 2). No change in color was observed in the absence of plant extract, under similar conditions which confirm the notion that plant extracts are the key players for the generation of NPs.

The samples were diluted 2.5 times for UV-Vis spectrophotometric analysis and the results indicated absorbance peaks around $440-460 \mathrm{~nm}$ which are specific for Ag NPs in the samples (Fig. 3). The results are in agreement with the literature data (Sankar et al. 2010; Sankar et al. 2014; Moodley et al. 2018; Behravan et al. 2019; Pirtarighat et al. 2019).

In the dark condition, the color of the Ag NPs reaction mixture did not change confirming the significance of light energy for the generation of Ag NPs (images not shown). The significance of light energy for the

Table 1 Total flavonoid and phenolic contents of $\boldsymbol{O}$. vulgare extracts

\begin{tabular}{|c|c|c|c|}
\hline Collection area & Extract name $O$. vulgare & $\begin{array}{l}\text { Total flavonoid content, mg (QE) ( } g \text { dry } \\
w t)^{-1}\end{array}$ & $\begin{array}{l}\text { Total phenolic content, } \\
\text { mg (GAE) (g dry wt) }\end{array}$ \\
\hline Kotayk & OV 1 & $30.22 \pm 0.25$ & $165.01 \pm 1.07$ \\
\hline Lori & OV 2 & $41.63 \pm 1.14$ & $185.26 \pm 2.05$ \\
\hline Tavush & OV 3 & $69.64 \pm 1.09$ & $202.67 \pm 1.27$ \\
\hline Gegharkunik & OV 4 & $53.53 \pm 0.75$ & $150.19 \pm 0.69$ \\
\hline
\end{tabular}




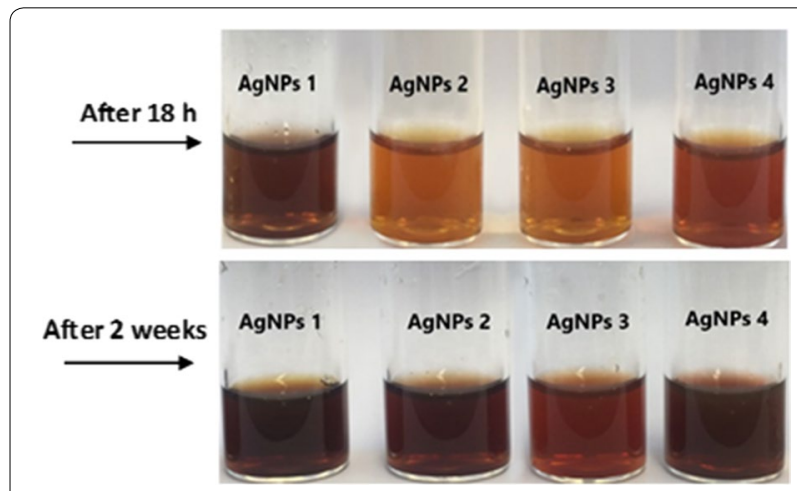

Fig. 2 The nano-suspensions were analyzed for stability and change in color with the passage of time and the results confirm the unstable nature of the samples

generation of NPs is also described by Rahman et al. (2019). Since the Ag NPs were not obtained in dark condition, the data described above only belongs to the samples exposed to light. Since Ag NPs belong to the category of plasmonic particles, they exhibit unusual optical properties. The electrons present in the conduction band at the surface of Ag NPs undergo collective oscillation when illuminated at specific wavelengths, a phenomenon known as surface plasmon resonance (SPR). SPR imparts high absorbing and scattering properties to the Ag NPs (Al-sharqi et al. 2019). The absorption peak of such particles may, therefore, shift depending on the size, shape and the environment surrounding the particles (Lee and Jun 2019). Previous studies have suggested that the SPR band shifts to a longer wavelength with increasing nanoparticle size known as redshift (Loiseau et al. 2019).

\section{Dynamic Light Scattering and Zeta Potential Studies}

DLS is a technique which measures the average particle size of nanoparticles in a sample. The principle of DLS operation is based on the method of laser beam diffraction. The incident light at the sample is mainly scattered by particles whose refractive index differs significantly from the solvent. The intensity of scattered light is detected by the DLS detector (Karmakar 2019). The results of DLS analysis revealed Z-average particle size of $58.81 \pm 0.65$ d.nm, $30.27 \pm 0.17$ d.nm, $30.20 \pm 045$ d.nm

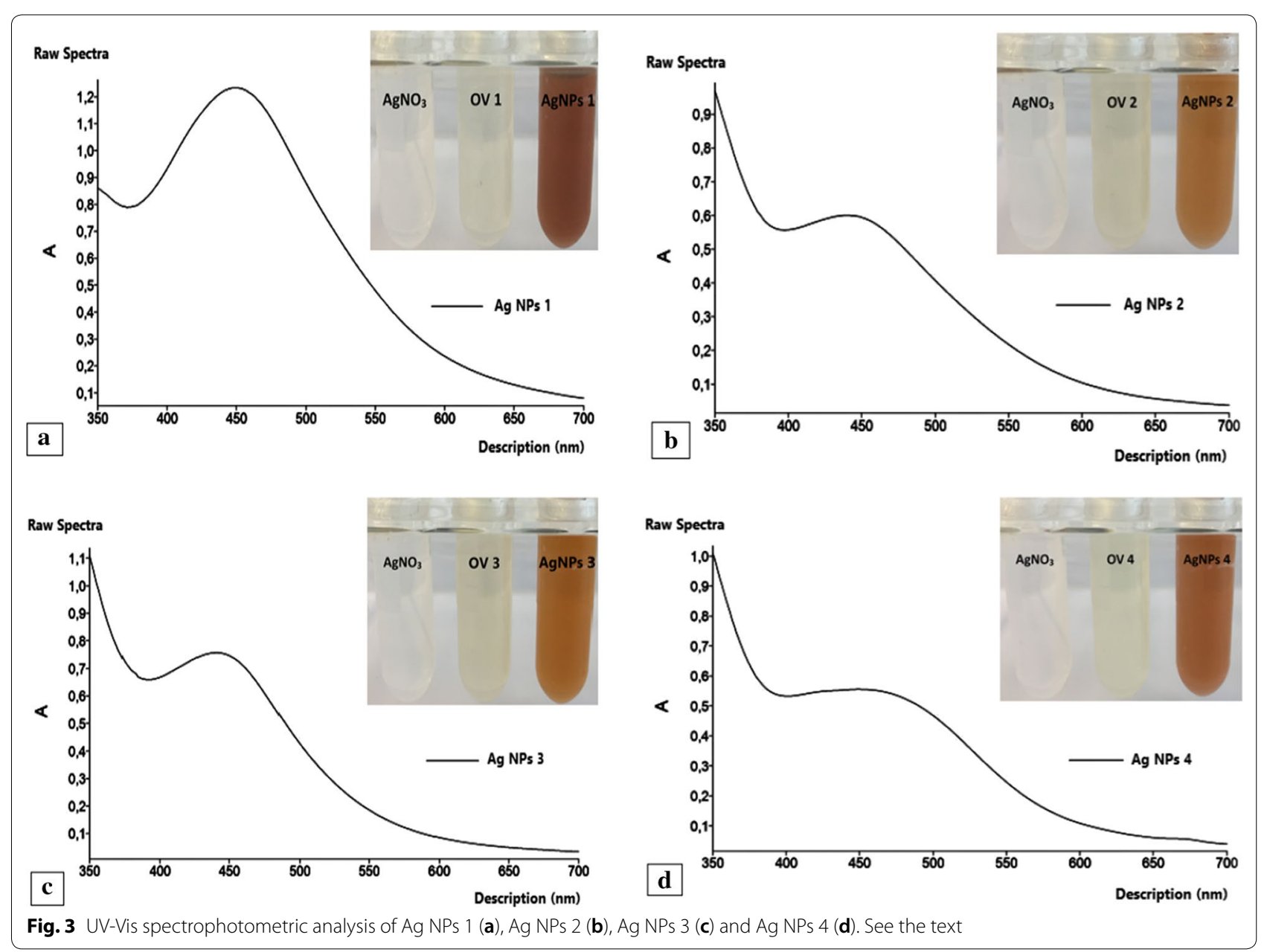


and 44.11 \pm 0.56 d.nm for Ag NPs 1, Ag NPs 2, Ag NPs 3 and Ag NPs 4, respectively (Fig. 4). Polydispersity Index (PDI) is also an important indicator of quality in relation to size distribution. PDI values for the samples ranged from 0.291 to 0.536 , which indicated that the samples are somewhat polydisperse in nature and the diameters of particle vary significantly (Danaei et al., 2018).

The $\xi$-potential is another significant parameter for understanding the surface charge and the tendency of aggregation of NPs. It is generally accepted that NPs with $\xi$-potential values of $\pm 0-10 \mathrm{mV}, \pm 10-20 \mathrm{mV}, \pm 20-3$ $0 \mathrm{mV}$, and $\pm 30 \mathrm{mV}$ are unstable, relatively stable, moderately stable, and highly stable, respectively (Bhattacharjee, 2016). The arguments regarding the dependence of the stability of NPs on the $\xi$-potential differ slightly in the literature (Kumar and Dixit 2019). The $\xi$-potential values of $-16.90 \pm 1.13 \mathrm{mV},-21.30 \pm 0.40 \mathrm{mV},-22.50 \pm 0.55 \mathrm{mV}$ and $-26.70 \pm 0.23 \mathrm{mV}$ were recorded for the Ag NPs $1, \mathrm{Ag}$ NPs 2, Ag NPs 3 and Ag NPs 4, respectively. NPs of these $\xi$-potential values are still prone to agglomeration, which may lead to further aggregation.

\section{SEM-EDX analysis}

SEM was performed to determine the particle size distribution of Ag NPs. SEM images confirmed that that Ag NPs were obtained in small sizes ranging from 1 to $50 \mathrm{~nm}$, as shown in Fig. 5. In the case of Ag NPs 2, Ag NPs 3 and Ag NPs 4 sizes of $1-25 \mathrm{~nm}$ prevailed, whilst in the case of Ag NPs 1, the predominant size was $30-50 \mathrm{~nm}$.
EDX was employed to confirm the elemental composition of the reaction mixture (Menon et al. 2017). The EDX analysis presented the spectral signal in silver region confirming the presence of Ag NPs. The spectral signals of carbon, oxygen, chlorine, and sulfur were also observed, which could be associated to the presence of phytochemical constituents of plant extracts adsorbed at or near the surface of metal NPs.

\section{Inductively coupled plasma-optical emission spectroscopy analysis}

The total Ag content was determined exploiting inductively coupled plasma-optical emission spectrometry (ICP OES). It is important to note that this method is not able to differentiate between Ag ions and Ag NPs and provides the cumulative content of both forms (Campos et al. 2017). Nevertheless, the analysis provides details about the quality of the samples. According to the results of ICP-OES Ag NPs were obtained in good amount. The highest quantity was achieved for Ag NPs $3\left(110.1 \pm 0.2 \mathrm{mg} \mathrm{L}^{-1}\right)$ followed by Ag NPs $2\left(107.3 \pm 1.5 \mathrm{mg} \mathrm{L}^{-1}\right)$. A slightly lower quantity was achieved for Ag NPs $4\left(106.7 \pm 1.1 \mathrm{mg} \mathrm{L}^{-1}\right)$ and the least amount was observed for Ag NPs $1\left(103.9 \pm 0.8 \mathrm{mg} \mathrm{L}^{-1}\right)$. The slight differences in the achieved quantities are of particular interest since the amount of $\mathrm{AgNO}_{3}$ initially employed for all the samples was same. These differences in quantities can be explained considering the operating principle of ICP-OES, where only small particles may be detected and large particles may go to waste. According to the ICP-OES, the lowest Ag concentration
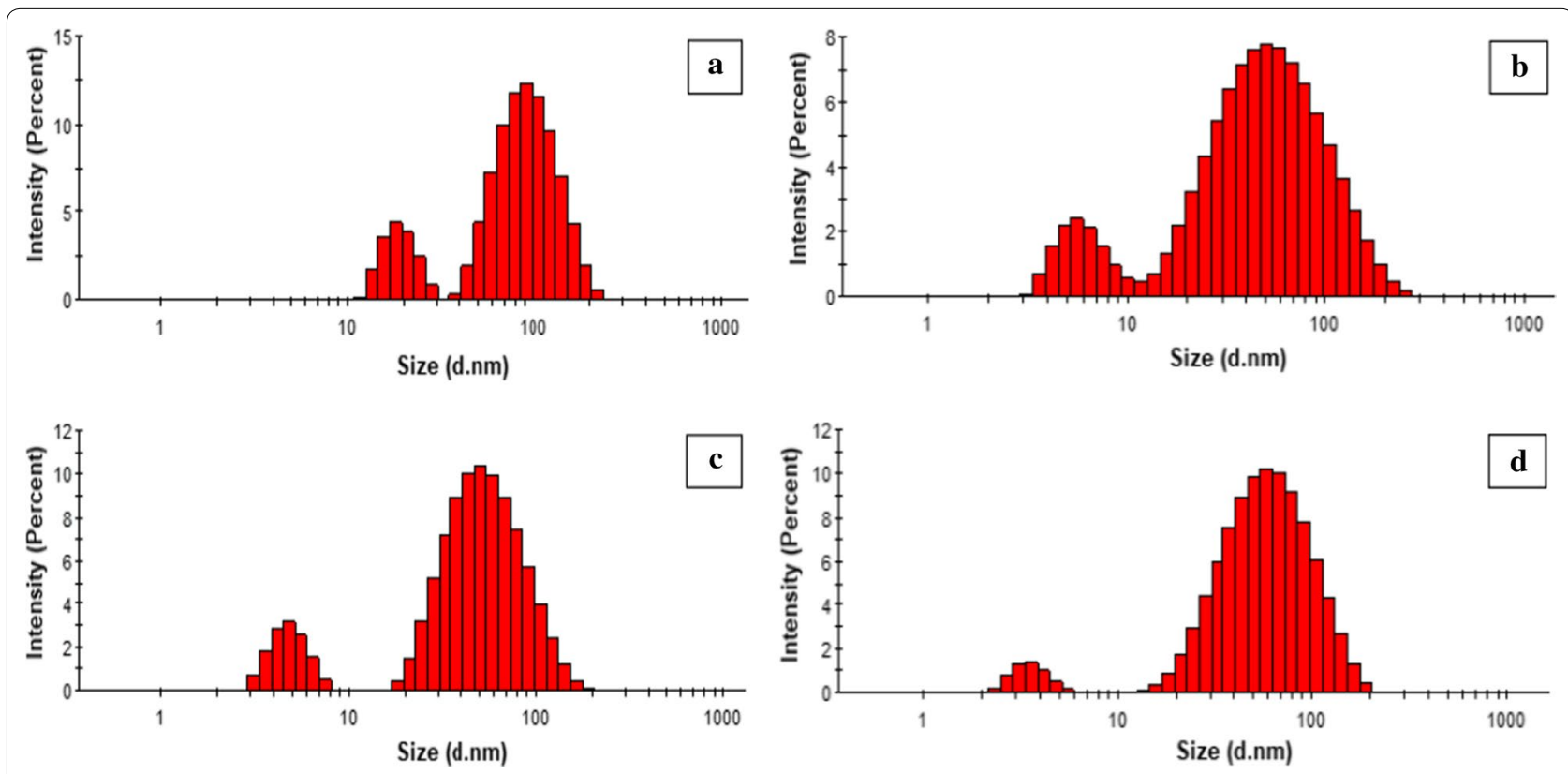

Fig. 4 DLS analysis of Ag NPs: Ag NPs 1 (a), Ag NPs 2 (b), Ag NPs 3 (c) and Ag NPs 4 (d). See the text 

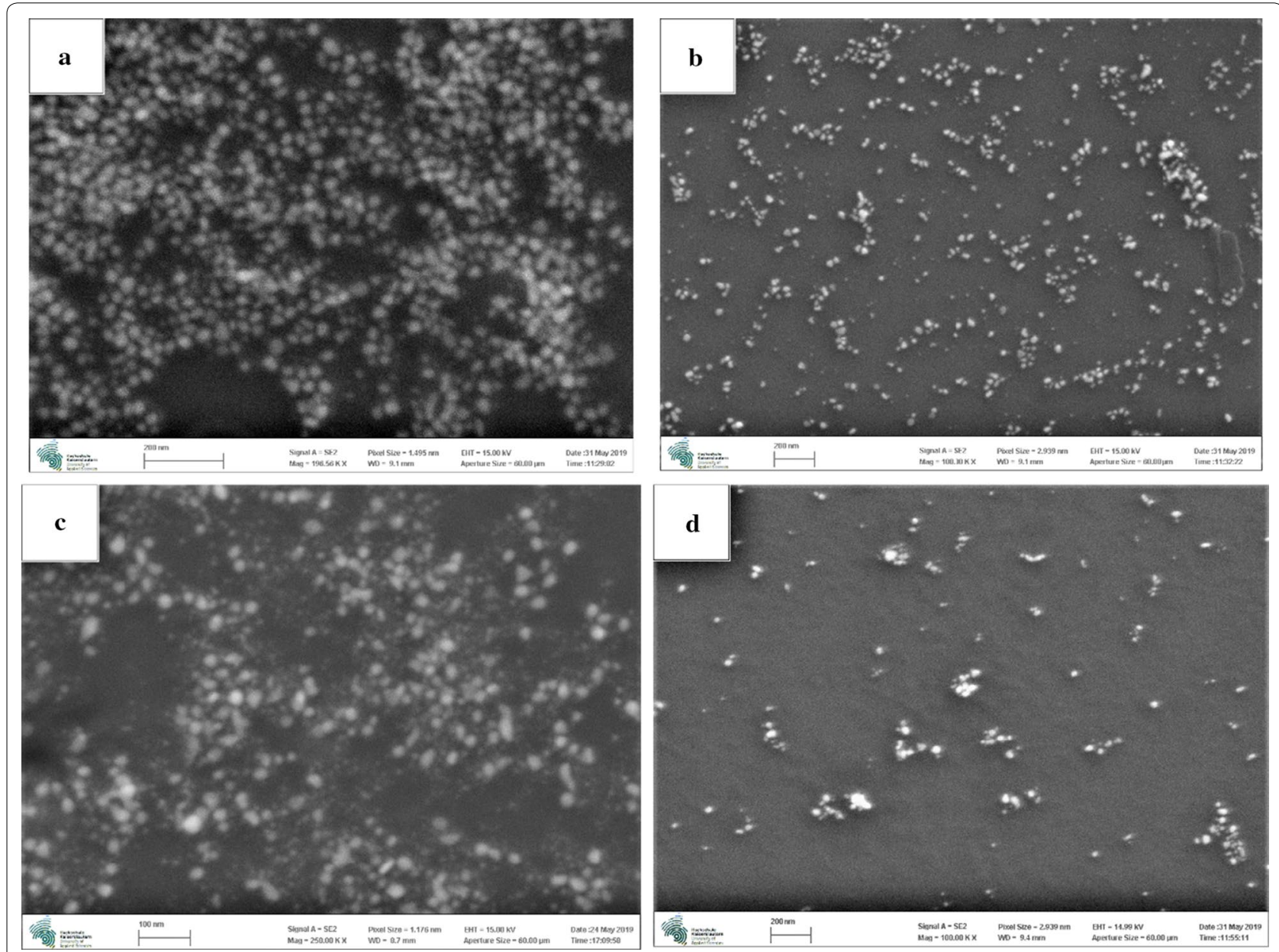

Fig. 5 SEM analysis of Ag NPs: Ag NPs 1 (a), Ag NPs 2 (b), Ag NPs 3 (c), Ag NPs 4 (d). See the text

was achieved in case of Ag NPs 1, which indicates that this sample contained aggregated particles or Ag oxides, while the highest $\mathrm{Ag}$ content among all samples was achieved for Ag NPs 3, confirming the good quality of this sample.

\section{Antibacterial activity of Ag NPs}

Based on the excellent results of characterization, $\mathrm{Ag}$ NPs 3 was selected for the antibacterial activity along with the relevant extract (OV3). The antibacterial activity was evaluated against several bacterial strains in terms of zone of inhibition and the antibacterial activity of $\mathrm{Ag}$ NPs 3 was compared with the activity of chemically synthesized colloidal Ag NPs $(\mathrm{P}>0.05)$ (as reference sample) and standards $(\mathrm{p}<0.05)$, as presented in Fig. 6 . The plant extract alone did not exhibit marked antibacterial activity (data not shown). The antibacterial activity of biologically synthesized Ag NPs 3 in some cases was comparable to chemically produced colloidal Ag NPs at the same concentration.
To investigate the stability in the activity of Ag NPs the MIC values were presented, which were 13.75, 9.16, $18.35,18.35,18.35$ and $11 \mu \mathrm{gmL}^{-1}$ observed for Ag NPs 3 against St. aureus MDC 5233, B. subtilis WT-A17, E. coli VKPM-M17, S. typhimurium MDC 1754, E. coli DH5 $\alpha-$ pUC18 and E. coli pARG-25, respectively. The experiment was repeated with the same sample (Ag NPs 3) after 1 week, and a significant decrease in the antibacterial activity of Ag NPs 3 was observed whilst the colloidal Ag NPs retained the activity. This decrease in activity could be attributed to the possible aggregation of NPs.

In case of Gram-positive bacterial strains, the activity of colloidal and biosynthesized Ag NPs was almost similar, but in case of Gram-negative strains we had some diversity in the influence-E. coli VKPM-M17 was more sensitive to the biosynthesized NPs, compared to the colloidal ones (Fig. 6) $(\mathrm{p}<0.01)$. Ag NPs 3 inhibited the growth of $E$. coli strains even stronger than the standard (Fig. 6) $(\mathrm{p}<0.05)$. 


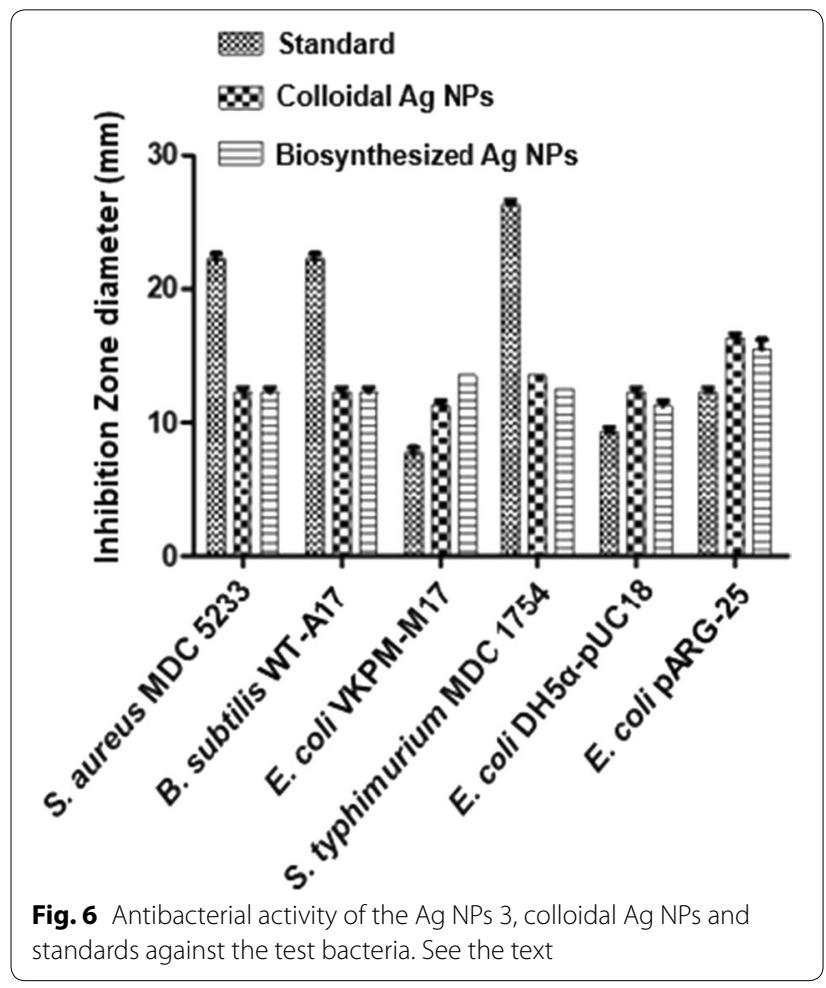

The growth kinetics assay was employed to understand the pattern of bacterial growth under the influence of biosynthesized Ag NPs and the related extract. A significant inhibition in growth of E. coli VKPM-M17 was observed for both samples i.e. extract and the Ag NPs 3 as presented in Fig. 7 .

The values of $\mu_{2}$ and $g_{2}$ were also calculated for $E$. coli VKPM-M17 treated with OV 3 extract $\left(\mathrm{t}_{0}=0\right.$ and $\left.\mathrm{t}=1 \mathrm{~h}\right)$. The values of calculated growth rate constants for Ag NPs 3 and OV3 extract were $0.529 \mathrm{~h}^{-1}$ and $0.456 \mathrm{~h}^{-1}$, respectively. The mean generation time of $1.31 \mathrm{~h}$ and $1.52 \mathrm{~h}$ was calculated for E. coli VKPM-M17 treated with Ag NPs 3 and OV 3 extract, respectively.

\section{Discussion}

Ag NPs synthesized using Oreganum leaves extract have small sizes, they are polidisperse, having different Ag content and tendency to aggregation. Among plants from different regions used to synthesize NPs, Ag NPs 3 (see Materials and methods and Results) were determined with the highest antibacterial activities.

Geographical origin and the climate conditions of plant growth significantly influence the quantitative and qualitative composition of phytochemicals present in plants, as a result, O. vulgare leaves extracts exploited in this study exhibited different antioxidant and reducing activities, which led to the synthesis of NPs of varying degrees of stability. Thus, the chemical composition of

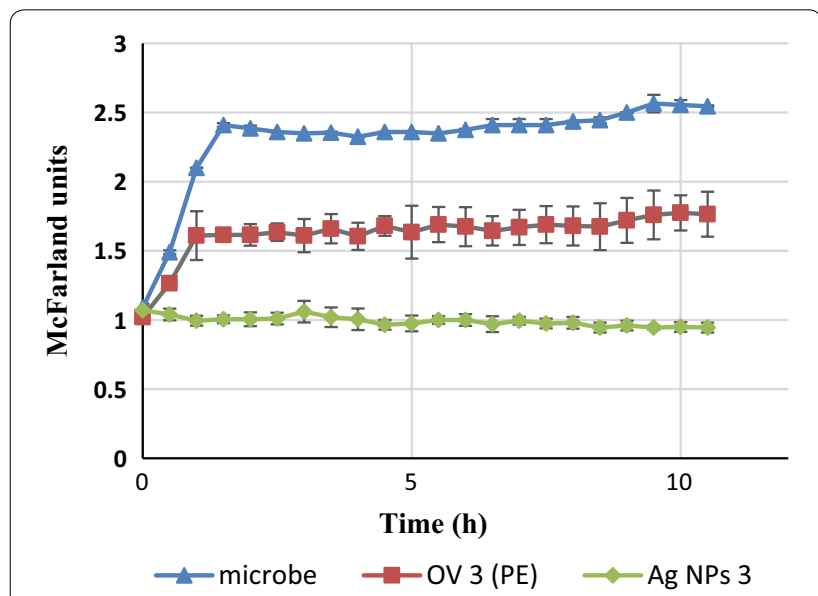

Fig. 7 The growth curve of E. coliVKPM-M17 compared with the growth curves of bacteria under the influence of OV 3 and Ag NPs 3

plant extracts is very important, and by changing it, more stable particles can be synthesized. We suggest further research using separate phyto-molecules instead of plant extracts that contain a mixture of different phyto-molecules. This may help to better understand, which phytomolecules are more favorable for the green synthesis of Ag NPs.

The antibacterial effect of Ag NPs on Gram-positive and Gram-negative bacterial strains occurs differently since the structure and the charge of the cell wall of these bacteria are varying. Gram-negative bacteria are more susceptible to Ag NPs than Gram-positive bacteria, as described also by different authors (Mnatsakanyan and Trchounian 2018; Aghajanyan et al. 2020).

To explain antibacterial effects, it should be noted that, first of all, Ag NPs damage the cell membrane (Trchounian et al. 2018; Gabrielyan and Trchounian 2019). Moreover, Ag NPs alter the permeability of the cell membrane and disrupt the functioning of the bacterial respiratory chain or the proton $\mathrm{F}_{\mathrm{O}} \mathrm{F}_{1}$-ATPase, which are ones of the causes of cell death (Trchounian et al. 2018; Gabrielyan and Trchounian 2019). In addition, Ag NPs induce the formation of reactive oxygen species (ROS) (e.g., superoxide, hydroxyl radicals, singlet oxygen) and inhibit the expression of antioxidant enzymes (i.e., superoxide dismutase and hydroperoxidase), as a result of which the bacterial cell is exposed to oxidative stress and dies (Qing et al. 2018). Ag NPs exhibit a genotoxic effect that causes various damages to DNA sequences. In the presence of Ag NPs, DNA loses its ability to replicate. It can also lead to a malfunction of the repair system (Morones et al. 2005).

The shapes of NPs are also of great importance by the means of influencing on the cell membrane of bacteria. 
In this regards it would be valuable to mention that socalled green Ag NPs of round-shaped forms are more active, compared to the other forms (Trchounian et al. 2018). Ag NPs obtained by the reduction of plant origin substances extracted from the $O$. vulgare leaves are also possessing round shapes. The similar results have been also described by Aghajanyan et al. (2020), who used as reducing agents the extracts obtained from the Artemisia annua. But in contrast to the NPs obtained by using Artemisia extracts, the antibacterial activity of NPs obtained by the reduction of $\mathrm{AgNO}_{3}$ with the O. vulgare leaves extracts possesses 7-9 times higher activity.

In general, the biosynthesis of Ag NPs employing plant extracts offers a simple, inexpensive and safe method, which is widely accepted by several researchers throughout the world (Kumar and Yadav 2009). Some literature data are suggesting the synergistic effect of biologically synthesized Ag NPs and some plant origin substances against different bacterial strains, including multidrugresistant bacteria, reducing their MIC values and reducing the time of action compared to bio-Ag NPs used alone (Scandorieiro et al. 2016). Biologically synthesized Ag NPs exhibited good antibacterial activity against antibiotic non-resistance as well as antibiotic-resistance bacterial stains, although such particles cannot be utilized for long time due to instability and a tendency to aggregation. Despite this, improving the stability of Ag NPs, these nanoparticles can be used in various biomedical and biotechnological applications (Nakamura et al. 2019).

\section{Acknowledgements}

We would like to acknowledge Dr. Armenuhi Moghrovyan, Department of Pharmacognosy, Yerevan State Medical University, Armenia, for providing plant extracts.

\section{Authors' contributions}

SH performed the experimental part under the direct supervision of NS. MJN helped in performing the experiments, provided advance. AT directed the study, provided advances and critical comments. All other authors contributed to the revision, critically commented and edited the manuscript. All authors read and approved the manuscript.

\section{Funding}

The research was supported by Basic support of Committee of Science, Ministry of Education, Science, Culture and Sport of Armenia, to Yerevan State University, as well as EU Erasmus + Exchange Program by Saarland University, Germany, to SH.

\section{Availability of data and materials}

All data generated or analyzed duringthis study are included in this published article.

\section{Ethics approval and consent to participate}

Not applicable.

\section{Consent for publication}

Not applicable.

\section{Competing interests}

The authors declare no conflict of interest.

\section{Author details}

${ }^{1}$ Department of Biochemistry, Microbiology and Biotechnology, Biology Faculty, Yerevan State University, 1 Alex Manoogian Str, 0025 Yerevan, Armenia.

2 Division of Bioorganic Chemistry, School of Pharmacy, Saarland University,

Saarbrucken 66123, Germany.

Received: 21 August 2020 Accepted: 27 August 2020

Published online: 05 September 2020

\section{References}

Aghajanyan A, Gabrielyan L, Schubert R, Trchounian A (2020) Silver ion bioreduction in nanoparticles using Artemisia annua L extract: characterization and application as antibacterial agents. AMB Express 10:66. https://doi. org/10.1186/s13568-020-01002-w

Alexander JW (2009) History of the medical use of silver. Surg Infect 10(3):289292. https://doi.org/10.1089/sur.2008.9941

Al-sharqi A, Apun K, Vincent M, Kanakaraju D, Bilung LM (2019) Enhancement of the antibacterial efficiency of silver nanoparticles against gram-positive and gram-negative bacteria using blue laser light. Int J Photoenergy 2019:1-12. https://doi.org/10.1155/2019/2528490

Anna K, Speruda M, Krzy E (2018) Similarities and differences between silver ions and silver in nanoforms as antibacterial agents. Int J Mol Sci 19(2):444. https://doi.org/10.3390/ijms19020444

Behravan M, Hossein A, Naghizadeh A, Ziaee M, Mahdavi R, Mirzapour A (2019) Facile green synthesis of silver nanoparticles using Berberis vulgaris leaf and root aqueous extract and its antibacterial activity. Int J Biol Macromol. 124:148-154. https://doi.org/10.1016/j.ijbiomac.2018.11.101

Bhattacharjee S (2016) DLS and zeta potential - What they are and what they are not? J Control Release 235:337-351. https://doi.org/10.1016/j.jconr el.2016.06.017

Campos V, DeAlba-Montero I, Ruiz F, Girón C, García-García E, Loredo-Tovías M (2017) Simple and rapid method for silver nanoparticles incorporation in polymethyl methacrylate (PMMA) substrates. Superficies y Vacío. 30(4):51-55

Danaei M, Dehghankhold M, Ataei Davarani SFH, Javanmard R, Dokhani A, Khorasani S, Mozafari MR (2018) Impact of particle size and polydispersity index on the clinical applications of lipidic nanocarrier systems. Pharmaceutics 10(2):1-17. https://doi.org/10.3390/pharmaceutics10020057

Dhand C, Dwivedi N, Loh XJ, Ying ANJ, Varma NK, Beuerman RW, Lakshminarayanan R, Ramakrishna S (2015) Methods and strategies for the synthesis of diverse nanoparticles and their applications: a comprehensive overview. RSC Adv 5(127):105003-105037. https://doi.org/10.1039/ C5RA19388E

Gabrielyan L, Trchounian A (2019) Antibacterial activities of transient metals nanoparticles and membranous mechanisms of action. World J MicrobBiotechnol. 35(10):162

Genwali GR, Acharya PP, Rajbhandari M (2013) Isolation of gallic acid and estimation of total phenolic content in some medicinal plants and their antioxidant activity. Nepal J Sci Technol. 14(1):95-102. https://doi. org/10.3126/njst.v14i1.8928

Ghasemi K, Sciences SA, GhasemiY Ebrahimzadeh MA (2009) Antioxidant activity, phenol and flavonoid contents of 13 Citrus species peels and tissues. Pak J Pharm Sci. 22(3):277-281

Karmakar S (2019) Particle size distribution and zeta potential based on dynamic light scattering : techniques to characterise stability and surface distribution of charged colloids particle. Recent Trends Materials: Physics Chem 1st ed., Studium Press Pvt Ltd., India, pp117-159

Kondeti VSSK, Gangal U, Yatom S, Bruggeman PJ (2017) $\mathrm{Ag}^{+}$reduction and silver nanoparticle synthesis at the plasma-liquid interface by an RF driven atmospheric pressure plasma jet: mechanisms and the effect of surfactant. J Vac Sci Technol A 35(6):1-19

Kraemer SA, Ramachandran A, Perron GG (2019) Antibiotic pollution in the environment: from microbial ecology to public policy. Microorganisms 7(6):1-24. https://doi.org/10.3390/microorganisms7060180

Kumar A, Dixit CK (2019) Methods for characterization of nanoparticles. Adv Nanomed Del Therap Nucl Acids. https://doi.org/10.1016/B978-0-08100557-6.00003-1 
Kumar V, Yadav SK (2009) Plant-mediated synthesis of silver and gold nanoparticles and their applications. J ChemTechnolBiotechnol. 84:151-157. https ://doi.org/10.1002/jctb.2023

Lawhavinit O, Kongkathip N, Kongkathip B 2010 Antimicrobial activity of curcuminoids from Curcuma longa L. on pathogenic bacteria of shrimp and chicken. Kasetsart J (Nat. Sci.)44(3):364-371

Lee SH, Jun BH (2019) Silver nanoparticles: synthesis and application for nanomedicine. Int J Mol Sci 20(4):865. https://doi.org/10.3390/ijms20040865

Loiseau A, Asila V, Boitel-aullen G, Lam M (2019) Silver-based plasmonic nanoparticles for and their use in biosensing.Biosensors (Basel)9(2):78. https:// doi.org/10.3390/bios9020078

Maclean AM, White CE, Fowler JE, Finan TM (2009) Identification of a Hydroxyproline transport system in the legume endosymbiont Sinorhizobium meliloti. Mol Plant-Microbe Interact. 22(9):1116-1127. https://doi. org/10.1094/MPMI-22-9-1116

Mcshan D, Ray PC, Yu H (2014) Molecular toxicity mechanism of nanosilverv. J Food Drug Anal. 22(1):116-127. https://doi.org/10.1016/j.jfda.2014.01.010

Menon S, Agarwal H, Kumar SR, Kumar SV (2017) Green synthesis of silver nanoparticles using medicinal plant Acalypha indica leaf extracts and its application as an antioxidant and antimicrobial agent against foodborne pathogens. Int J App Pharm. 9(5):42-50. https://doi.org/10.22159/ ijap.2017v9i5.19464

Mnatsakanyan N, Trchounian A (2018) Nanocomposite filter made from porous mineral tuff with absorbed silver nanoparticles and its application for disinfection of water. J Water Suppl 67:127-136. https://doi. org/10.2166/aqua.2018.161

MoghrovyanA Sahakyan N, Babayan A, Chichoyan N, Petrosyan M, Trchounian A (2019) Essential Oil and Ethanol Extract of Oregano (Origanum vulgare L) from ArmenianFlora as a Natural Source of Terpenes, Flavonoids and other Phytochemicals withAntiradical, Antioxidant, Metal Chelating, Tyrosinase Inhibitory and AntibacterialActivity. Curr Pharmaceut Design. 25(16):1809-1816. https://doi.org/10.2174/13816128256661907020 95612

Moodley JS, Babu S, Krishna N, Pillay K (2018) Green synthesis of silver nanoparticles from Moringa oleifera leaf extracts and its antimicrobial potential. Adv Nat Sci Nanosci Nanotechnol. 9(1):1-9. https://doi.org/10.1088/20436254/aaabb2

Morones JR, Elechiguerra JL, Camacho A, Holt K, Kouri JB, Ramirez JT, Yacaman MJ (2005) The bactericidal effect of silvernanoparticles. Nanotechnology 16:2346-2353. https://doi.org/10.1088/0957-4484/16/10/059

Nakamura S, Sato M, Sato Y, Ando N, Takayama T, Fujita M, Ishihara M (2019) Synthesis and Application of Silver Nanoparticles (Ag NPs) for the Prevention of Infection in Healthcare Workers. Int J Mol Sci 20:3620. https://doi. org/10.3390/ijms20153620

Pirtarighat S, Ghannadnia M, Baghshahi S (2019) Green synthesis of silver nanoparticles using the plant extract of Salvia spinosa grown in vitro and their antibacterial activity assessment. J Nanostructure Chem. 9(1):1-9. https://doi.org/10.1007/s40097-018-0291-4

Qing Y, Cheng L, Li R, Liu G, Zhang Y, Tang X, Wang J, Liu H, Qin Y (2018) Potential antibacterial mechanism of silver nanoparticles and the optimization of orthopedic implants by advanced modification technologies. Int L Nanomed 13:3311-3327. https://doi.org/10.2147/IJN.S165125

Rahman A, Kumar S, Bafana A, Lin J, Dahoumane SA, Je C (2019) A Mechanistic View of the Light-Induced Synthesis of Silver Nanoparticles using extracellular polymeric substances of Chlamydomonas reinhardtii. Molecules 24:3506. https://doi.org/10.3390/molecules24193506

Rautela A, Rani J, Das MD (2019) Green synthesis of silver nanoparticles from Tectona grandis seeds extract: characterization and mechanism of antimicrobial action on different microorganisms. J. Anal Sci Technol. 10(1):5 https://doi.org/10.1186/s40543-018-0163-z

Salari S, Esmaeilzadeh S, Samzadeh-kermani A (2019) In-vitro evaluation of antioxidant and antibacterial potential of green synthesized silver nanoparticles using Prosopis farcta fruit extract. Iran J Pharm Res. 18(1):430-445

Sankar R, Kumbhakar P, Mitra AK (2010) Green synthesis of silver nanoparticles and its optical properties. Digest J Nanomater Biostruct. 5(2):491-496
Sankar R, Karthik A, Prabu A, Karthik S, Shivashangari KS, Ravikumar V (2014) Origanum vulgare mediated biosynthesis of silver nanoparticles for its antibacterial and anticancer activity. Colloids Surf, B 108:80-84

Scandorieiro S, Camargo LC, Lancheros CAC, Yamada-Ogatta SF, Nakamura CV Oliveira AG, Andrade CGTJ, Duran N, Nakazato G, Kobayashi RKT (2016) Synergistic and additive effect of oregano essential oil and biological silver nanoparticles against multidrug-resistant bacterial strains. Front Microbiol. 7:760. https://doi.org/10.3389/fmicb.2016.00760

Shaik MR, Khan M, Kuniyil M, AI-Warthan A, Alkhathlan HZ, Siddiqui MRH, Shaik JP, Ahamed A, Mahmood A, Khan M, Adil SF (2018) Plant-extract-assisted green synthesis of silver nanoparticles using Origanum vulgare L extract and their microbicidal activities. Sustainability. 10(4):913. https://doi. org/10.3390/su10040913

Soghomonyan DR, Mnatsakanyan NS, Trchounian AH (2019) To the mechanism of antibacterial action of colloidal silver: changes in membraneassociated proton ATPase activity in Escherichia coli and Enterococcus faecalis. Biolog J Armenia. 3(71):73-78

Srikar SK, Giri DD, Pal DB, Mishra PK, Upadhyay SN (2016) Light induced green synthesis of silver nanoparticles using aqueous extract of Prunus amygdalus. Green Sustain Chem. 6:26-33. https://doi.org/10.4236/gsc.2016.61003

Srirangam GM, Rao KP (2017) Synthesis and charcterization of silver nanoparticles from the leaf extract of Malachra Capitata $(\mathrm{L})$. Rasayan J Chem. 10(1):46-53. https://doi.org/10.7324/rjc.2017.1011548

Szermer-olearnik B, Zwolińska K (2014) Comparison of microbiological and physicochemical methods for enumeration of microorganisms. Postepy Hig Med Dosw. 68:1392-1396. https://doi.org/10.5604/17322693.11300 86

Tarannum N, Gautam YK (2019) Facile green synthesis and applications of silver nanoparticles: a state-of-the-art review. RSC Adv. 9(60):34926-34948. https://doi.org/10.1039/c9ra04164h

Trchounian A, Gabrielyan L, Mnatsakanyan N (2018) Nanoparticles of various transition metals and their applications as antimicrobial agents. In Saylor Y, IrbyV, Editors. Metal Nanoparticles: Properties, Synthesis and Applications, Hauppauge NY, USA: Nova Science Publ, 161-211

Tungmunnithum D, Thongboonyou A, Pholboon A (2018) Flavonoids and other phenolic compounds from medicinal plants for pharmaceutical and medical aspects: an Overview. Medicines. 5(3):93. https://doi. org/10.3390/medicines5030093

Xu Y, Zhao H, Zhang M, Li C, Lin X, Sheng J (2011) Variations of antioxidant properties and $\mathrm{NO}$ scavenging abilities during fermentation of Tea. Int J Mol Sci 12(7):4574-4590. https://doi.org/10.3390/ijms12074574

Yong NL, Ahmad A, Mohammad AW (2013) Synthesis and characterization of silver oxide nanoparticles by a novel method. Int J Sci Eng Res. $4(5): 155-158$

\section{Publisher's Note}

Springer Nature remains neutral with regard to jurisdictional claims in published maps and institutional affiliations.

\section{Submit your manuscript to a SpringerOpen ${ }^{\circ}$ journal and benefit from:}

- Convenient online submission

- Rigorous peer review

- Open access: articles freely available online

- High visibility within the field

- Retaining the copyright to your article

Submit your next manuscript at springeropen.com 